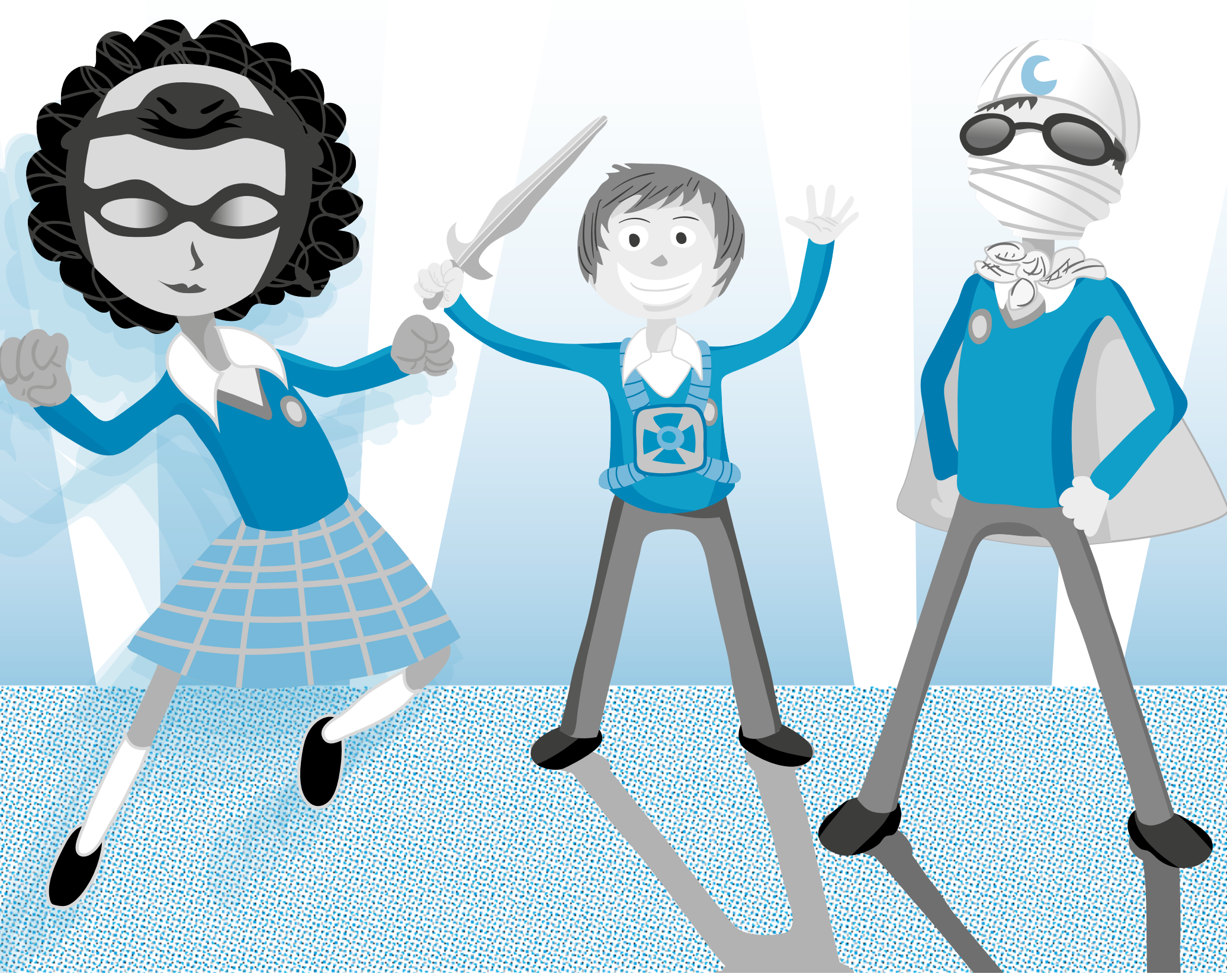

\title{
La axiología subyacente en el lenguaje de las series de dibujos animados presentados en la televisión colombiana
}

The underlying axiology in the language of the cartoon series presented on television colombiana

A axiologia subjacente na linguagem da série de desenhos animados apresentada na televisao colombiana 
Yebrail Castañeda Lozano ${ }^{1}$
Ycastaneda@unisalle.edu.co
1 Docente de la Universidad de la Salle.

Maestría en Educación de la Pontificia Universidad Javeriana.

Fecha de recepción: 7 de Octubre de 2013 / Fecha de aprobación: 8 de noviembre de 2013

\section{La axiología subyacente en el lenguaje de las series de dibujos animados presentados en la televisión colombiana}

\section{Resumen}

El siguiente artículo tiene el propósito de visibilizar la axiología subyacente en las series de dibujos animados presentados en Colombia. Para realizar el análisis se abordó la serie animada más significativa de cada una de las décadas vistas, y para explorar el marco axiológico ético se abordaron las canciones introductorias de cada serie. En el plano estético se valoró el vestuario, los colores y ademanes, tanto de los héroes como de los superhéroes. El método utilizado se fundamentó en las categorías del gusto de Calabrese: Teratología, Adalidología, Fractales y Entropía.

Palabras clave: Axiología, Lenguaje y Serie Animada.

\section{The underlying axiology in the language of the cartoon series presented on television colombiana}

\section{Summary}

The following article is intended to visualize the underlying axiology contained in the cartoon series presented in Colombia. To perform this analysis addressed the most significant animated series from each of the decades. To explore the ethical value framework addressed the introductory song of each series and the aesthetic were assessed costumes, the colors and gestures both heroes and superheroes. The method used was the categories of taste Calabrese: Teratology, Adalidology, Fractals and Entropy.

Keywords: Axiology, Language and Cartoon Series.

\section{A axiologia subjacente na linguagem da série de desenhos animados apresentada na televisao colombiana}

\section{Resumo}

0 artigo a seguir é destinado a visualizar a axiologia subjacente contido na série de desenhos animados apresentados na Colômbia. Para realizar esta análise dirigida a série animada mais significativo de cada uma das últimas décadas. Para explorar o quadro valor ético abordado a música de introdução de cada série ea estética foram avaliadas costumes, as cores e gestos de ambos os heróis e super-heróis. 0 método utilizado foram as categorias de Calabrese gosto: teratologia, Adalidología, Fractais e entropia.

Palavras-chave: Axiologia, Linguagem e Animated Series. 


\section{Introducción}

L os escenarios escolares han diseñado construido y constituido su propio patrimonio axiológico desde los principios y fundamentos que se encuentran en los diferentes proyectos educativos institucionales (PEI). Estas directrices se han dinamizado y modulado en las acciones concretas de la enseñanza y el aprendizaje que se realizan en los centros escolares: en la presentación de los discursos por parte de los directivos, docentes y padres de familia, que se realizan ya sea de forma ordinaria o extraordinaria, es propia del mundo de la escuela; también los rastros axiológicos, tanto en lo ético como en lo estético, que dejan huellas en las actuaciones de la comunidad escolar, representadas desde las acciones del rector hasta las actitudes de quienes trabajan en los servicios generales.

El dilema que se presenta es la distancia entre los principios y fundamentos teóricos en materia axiológica, con respecto a los dinamismos comportamentales de la comunidad escolar. Las razones de este divorcio son diversas; aquí se mencionarán algunas: 1) En los centros escolares no se reflexionan los problemas axiológicos contenidos en el PEI institucional, sino que se enseñan sentencias e imperativos de orden moralista y esteticista; 2) La cultura axiológica en la que actuamos se encuentra fuertemente conectada con el patrimonio ético y estético de las familias y de la sociedad. Esta asociación manifiesta una pluralidad de visiones, tanto en lo moral como en lo estético, que en muchos de los casos son adversas a la formación escolar; 3) Los medios de comunicación que, por su discurso inmediato y poco exigente, "performan" efectivamente los imaginarios axiológicos con reflexiones éticas y actuaciones estéticas, desde los ángulos de la imagen, de la virtualidad y del consumo.

El propósito de este artículo está en visibilizar la axiología subyacente en los discursos de los medios de comunicación. Si valoramos cada uno de los medios de comunicación en ellos se tiene una carga ética, estética y política. La radio tiene el sustrato axiológico en la información de noticias, en la presentación de canciones y en la mediación de entretenimiento. La televisión tiene el patrimonio axiológico en la presentación de imágenes de películas, programas culturales y de diversión. La Internet tiene su base axiológica en lo virtual, con la hipertextualidad de la comunicación y redes sociales, con la hiper- medialidad del sonido y de la imagen, y con la hiperinteractuación de la ubicuidad espacial y de la asincronización temporal.

Los discursos de los medios de comunicación han modulado relacionalmente las variantes axiológicas de la ética, la moral y la estética, que han dejado su impronta en la subjetividad en las diferentes generaciones. Estas modulaciones han transformado la percepción de las binariedades tradicionales de lo bueno y lo malo, de lo positivo y negativo, de lo feo y de lo bello, por nuevas demarcaciones dualistas que podrían denominarse formas distorsionadas de lo verdadero, lo bueno y lo bello. Para analizar la influencia de los medios de comunicación en las transformaciones, variaciones y nuevas referencias en las percepciones axiológicas de los sujetos, esta reflexión abordará los discursos televisivos, específicamente algunos programas o series de dibujos animados de las décadas de los setenta, ochenta, noventa y del nuevo milenio, que marcaron en su momento y seguirán marcando la valoración de los valores de las generaciones pasadas, presentes y futuras de jóvenes y de niños.

Desde esta perspectiva, se evaluarán los discursos axiológicos, en lo ético y estético, que presentan las series de dibujos animados utilizando la siguiente forma: las series de la década de los setentas: Centella; los programas de la década de los ochenta: He-Man; la serie de la década de los noventa: Caballeros del Zodiaco, y finalmente, en la década del actual milenio: Souh Park. El discurso ético se deducirá de las letras de las canciones introductorias de cada una de las series. Mientras que el discurso estético se inferirá de la tensión entre el héroe y el monstruo que presenta cada serie.

El diseño metodológico para el análisis de este artículo tiene su fundamento teórico en las categorías del gusto de la obra La Era Neobarroca de Omar Calabrese. Las categorías que se van aplicar son las concernientes a la "Inestabilidad y la metamorfosis" (Calabrese, 1999, p. 106), junto con las del "Desorden y el caos" (Calabrese, 1999, p. 132). La primera tiene que ver con las variantes del discurso adalidológico (estudios de los héroes) y el discurso teratológico (estudio de los monstruos). La segunda tiene que ver con las variantes de entropía (estudio de lo conforme y deforme) y los fractales (estudio de lo regular e irregular). 


\section{He-Man y los Amos del Universo. El discurso axiológico de lo monstruoso en los ochentas}

La serie He-Man (El-Hombre), o He-Man, los Amos del Universo, en su versión española, fue emitida en Colombia a mediados de los ochentas. Su canción introductoria se encuentra en inglés, sin embargo, es lo suficientemente sencilla ser traducida. Es una canción sumamente larga, por ello, se presentaran las tres estrofas más significativas en el plano axiológico.

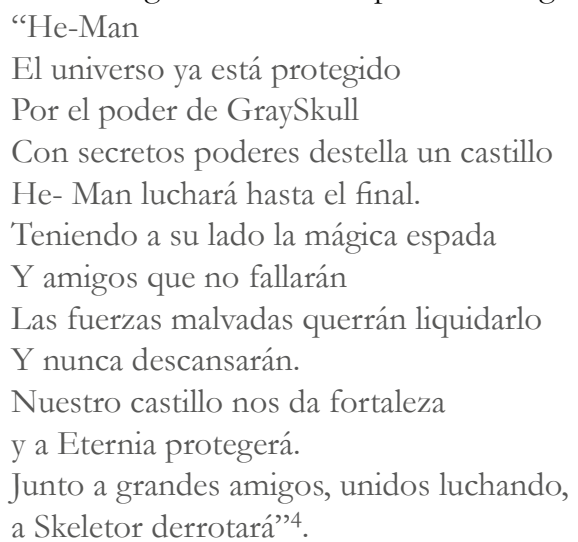

En las estrofas se contextualiza la serie; los acontecimientos transcurren en un exótico planeta llamado Eternia, cuna de un hombre poderoso llamado He-Man, quien se caracteriza por ser el hombre más poderoso del universo y lucha contra su mayor enemigo: Skeletor. He-Man y sus amigos protegen los secretos del Castillo de Grayskull, que es precisamente el lugar que salvaguarda la bondad del universo; está permanentemente acechado por las fuerzas del mal, encabezadas por Skeletor. El creador de la serie, Mattel, construye una mitología creativa que inicia en 1982 y llega hasta el 2002. Junto al superhéroe se encuentran personajes como Sheila (hermana), Stratos, Zodac, The Goddens y Ran-Man; mientras que el bando de Skeletor cuenta con BeastMan, Mer-Man, Evil-Lin, Faker y'Tri-Klop.

La estética del programa se desarrolla básicamente en el Castillo de Grayskull e incluye a Skeletor y He-Man. La diferencia axiológica de lo bueno y de lo malo se encuentra bien definida adjetivándose la bondad en los defensores, quienes pretenden aniquilar la maldad, acto exclusivo de los malvados. No obstante, esta serie de los ochentas marca un hito diferenciador con las series de las setentas: la distorsión de lo ético con respecto a lo estético. El Castillo de Grayskull, que guarda la bondad universal y los mayores secretos del universo, se encuentra rodeado por un lugar tenebroso y cadavérico, la puerta es la cavidad de un cráneo y las torres parecen construidas a partir de huesos.

Los protagonista de la serie He-Man y Skeletor, su vestuario y armamento son muy diferentes de los presentados en las series de décadas anteriores. He-Man es un hombre musculoso, semidesnudo, cuya piel es color naranja, con unas correas cuyo centro se encuentra una cruz a la altura del pecho, y le permiten cargar su poderosa espada. He-Man se transporta en su fiel amigo llamado Battle Cat, producto de la transformación de un tigre miedoso llamado Cringe, que es activado por el alzamiento de la espada y del grito de He-Man: "Por el poder de Greyscol" (He-Man, 2012, Cap. 2). Battle Cat es un tigre agresivo un monstruo con un cuerpo color rojo, salvo el verde de su pechera; un animal invencible que aporta significativamente a las labores de lucha de He-Man.

Skeletor presenta características similares a las de He-Man, un hombre semidesnudo y musculoso, pero su cabeza es un cráneo de color naranja; su vestido es un taparrabo azul con unas correas que sostienen la capa que cubre su cabeza. Usualmente se sienta en una silla hecha de un conjunto de huesos con una poltrona roja; su signo representativo es su cráneo descarnado y cadavérico que, según la mitología de Mattel, está de esta forma porque perdió su rostro en una pelea contra el padre de He-Man, el Rey Randor. A partir de este doloroso acontecimiento Skeletor pretende vengarse capítulo a capítulo y hacerse con los poderes y secretos del Castillo de Grayskull.

Las características del programa, presentando hombres musculosos y mujeres voluptuosas, semidesnudos, incorporando armaduras, se prolongan en series de los ochentas, como: Thundercats (2011, Cap. 1); Transformes (2008, Cap. 1); Halcones Galácticos (SilverHawks; 2012, Cap. 1); Robotech (2013, Cap. 1); Centuriones (2010, Cap. 1), y Mazinger Z (2011, Cap. 1). Aunque en estos nuevos se encuentra delimitada la dicotomía ética de lo bueno y lo malo, la estética sufre una distorsión que presenta lo bello como feo, en unos niveles de inestabilidad: la semidesnudez empieza ser tapada por las armaduras y finalmente estas armaduras son reemplazadas por máquinas manejadas por humanos.

4 Para ampliar acerca de la traducción de la canción es posible visitar la página: http://www.youtube.com/watch?v=vPmn7ZhuLrU 


\section{Caballeros del zodíaco. Las compañías inestables de los noventa}

Los Caballeros del zodiaco es una serie de anime japonés que en inglés fue llamada Saint Seiya (El Santo de Seiya), fue creada por Masami Kurumada y su publicación se dio a finales de los ochentas en Japón y en Europa, en América Latina y Colombia fue emitida entre 1990 y 1995 . La canción introductoria es herencia de las mangas morales de los ochenta que definen a los buenos como triunfadores sobre los malos. A continuación el fragmento de la canción de los Caballeros del Zodiaco:
"Los guardianes del zodiaco
Los guardianes del universo
Al triunfar el mal
Sin duda lo salen a combatir
Por un mundo ideal.
Caballeros del Zodiaco
Cuando lanzan su ataque
Entonando siempre su canción
La canción de los heroes.
Caballeros del Zodiaco
Contra las fuerzas demoníacas
Guardan siempre en su corazón
Coraje para vencer" 5 .

Los caballeros del zodiaco, utilizando el lenguaje del Presidente Bush Jr., pertenecen al eje del bien, mientras un sinnúmero de personajes enemigos, que van apareciendo sin previo aviso, pertenecen al eje del mal. Este anime se caracteriza por ser un pastich $^{6}$ literario postmoderno que incorpora aspectos antiguos, como la mitología griega y sus dioses, junto a la astrología clásica y sus constelaciones. A este dinamismo también se adhieren elementos medievales, religiosos budistas, sintoístas y cristianos, como los santos, caballeros o cruzados templarios, pero al mismo tiempo sus poderes provienen de fuerzas internas orientales: el cosmos. La canción gira alrededor de tres ideas axiológicas morales: La primera trata de que el mal no logra un mundo ideal; la segunda de que los Caballeros del Zodiaco tienen el corazón suficiente para vencer con coraje; la tercera es que estos caballeros denominados "santos" se caracterizan por ser los mejores.

El argumento de los Caballeros del Zodíaco se centra en un triángulo compuesto por los santos, Atenea y los santos negros.
Los santos, o jóvenes guerreros, tienen la misión de proteger la diosa griega Atenea de las fuerzas inesperadas del mal; tienen como armas su energía interior: el cosmos, sus puños, y, sobre todo, las armaduras. La historia gira alrededor de un torneo galáctico en el que participan los Caballeros y cuyo premio es la codiciada y misteriosa armadura dorada, que sin embargo hace parte de una serie en la que existen unos niveles intermedios, a los que pertenece, por ejemplo, la armadura de Pegaso, vestidura de Seiya, protagonista principal, que simboliza la justicia.

En principio todos los caballeros son enemigos por estar en el torneo, entre ellos Shiryu, cuya armadura es la del Dragón, por lo que el marco axiológico estético no presenta colores que diferencien el bien y del mal. Simplemente aparecen los guerreros dicen de dónde vienen, cuál es su propósito y comienza la lucha con su contendor, hasta lograr la victoria. Sin embargo, luego aparece en propiedad el eje del mal, encabezado por Ikki, Caballero del Fénix, seguido por los santos negros.

Los Caballeros del Zodíaco generaron improntas significativas en los jóvenes de la década de los noventa y principios del nuevo milenio, tanto en materia de axiología ética, como estética. En cuanto a la ética, la percepción de muerte fue distorsionada, pues caballeros que morían en un capítulo volvían aparecer en otro. La diferenciación entre el bien y el mal no resulta tan evidente, y era necesario no perderse de ningún capítulo para ver las sutilezas morales de cada uno de los personajes. El programa causó cierta adicción en la audiencia infantil y juvenil. En cuanto a lo estético, los niños y jóvenes comenzaron a imitar la forma de peinarse de los caballeros, su forma de hablar y sus ademanes característicos. Este fue el caso de Shun de Andrómeda quien a pesar de su apariencia débil y tierna derrota a su contrincante Jabú del Unicornio. No obstante, este caballero de apariencia hermosa e ingenua, se caracterizaba por su actitud pacifista, quien pretendía solucionar los conflictos sin acudir a la violencia.

Los caballeros del zodiaco fue una serie novedosa por su atemporalidad, su asincronía y su ubicuidad. La atemporalidad resulta del hecho de que no se desarrolla en un lugar temporal definido; la asincronía, gracias a que el tiempo cronológico no tiene especial relevancia; la ubicuidad se debe a

5 La canción fue tomada de la página de internet: http://www.youtube.com/watch?v=CiHbbwae5oA

6 El pastich es un vocablo de la postmodernidad literaria, y hace referencia al reciclaje de obras clásicas o antiguas a las que se le incorporan aspectos nuevos. Una de sus principales características es su amplio sincretismo. 
que es posible estar presente en varios lugares pero al mismo tiempo en ninguno. Estos fenómenos suceden gracias a que los caballeros-santos son, de alguna forma, personajes eternos, que no mueren y permanecen disponibles cuando Atenea los requiere. La dinámica de este programa se desplaza a otras series de esta década, como los Superamigos (2012, Cap. 1); los Supercampeones (2012, Cap. 1); Dragon Ball Z (2013, Cap. 1); Pokemón (2012, Cap. 1); Digimón (2012, Cap.
1) y Sailormoon (2013, Cap. 1). La sensibilidad de estos programas estriba en lo exagerado del vestuario, el hecho de que las acciones se desarrollan en grupos, los finales inesperados, el enigma en los diálogos, mucha actividad violenta y poco diálogo, se ingresa a las series de dibujos animados que incorporan la lógica tecnológica; los monstruos ni los héroes son claros y en algunos de los programas surgen tramas irregulares (fractales) y caóticas (entropía).

\section{South Park. La pesadilla de los padres de familia por su irreverencia y complejidad}

South Park es una serie que se caracteriza por el empleo de palabras groseras, actuaciones malsonantes y un humor ácido. Esta forma de irreverencia es la columna vertebral del programa que ha tenido un éxito desmedido en el mundo anglófono y latinoamericano. Tiene su origen en el año 1991, cuando Parker y Stone, en aquel entonces estudiantes de cine en la Universidad de Colorado, crearon un corto animado llamado Jesús vs. Frosty, también conocido como The Spirit of Christmas (El espíritu de la navidad). En este primer intento se devela alguno de los niños protagonistas que harán parte de la serie en la actualidad. El corto trataba sobre la confrontación entre el hombre nieve asesino, traído por Kenny, y el niño Jesús, quien lo decapita con su aureola. La polémica del programa inicia desde su canción; ahora un fragmento de ella:

\author{
"South Park \\ Eres un cabrón hijo puta, \\ un mamón y un pedorretas hijo puta, \\ eres un capullo y un cabrón, \\ te jodes por ser tan mamón. \\ Tu eres el cabrón hijo puta, \\ el mamón y el pedorretas hijo puta, \\ tu eres un mamón y un capullón, \\ que le falla el pez al muy cabrón"'7.
}

La serie ha provocado toda suerte de escándalos en familias y sociedades estadounidenses, canadienses y latinoamericanas. Trata sobre las aventuras de cuatro niños que viven en un pequeño pueblo llamado South Park, que se caracteriza por su pobreza, la mediocridad y los complejos de inferioridad social, que son

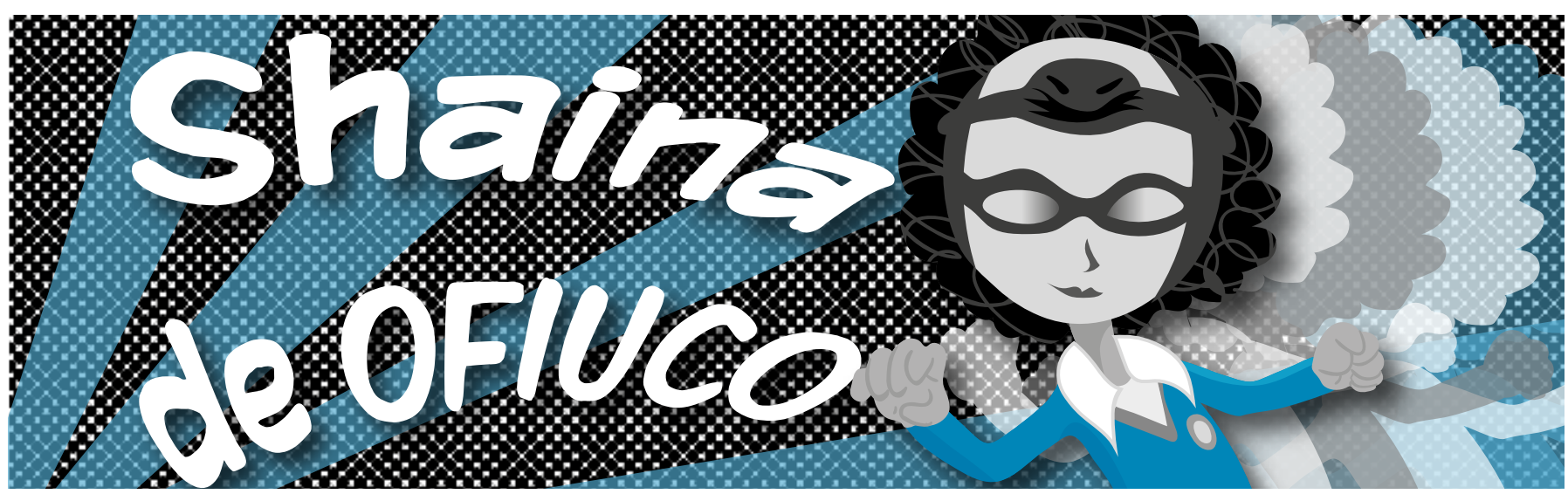

La canción fue tomada de la página de internet. http://www.youtube.com/watch?v=nvmXcXsb0ac 
puestos bajo el prisma de la crítica, la sátira, la ironía y el sarcasmo. Critica de lleno a la cultura americana, a la latinoamericana, a los gobiernos, creencias y religiones. El programa es una crítica que mediante un lenguaje tosco, presenta roles racionales en los niños e irracionales en los adultos, los niños son inteligentes y los adultos son idiotas. De forma irónica valora la cultura anglosajona mediante el humor negro y la tragicomedia y pone en entredicho mitos, tabúes y creencias políticas, sociales y religiosas, desafiando la ética, la estética y la axiología tradicional.

La serie se ha proyectado progresiva y positivamente por la dinámica de sus personajes, especialmente de los cuatro niños. Cada una de sus características ha conformado un ícono que no se tolera dentro de la sociedad. Este es el caso de Stan, quien se comporta como el más adulto de los cuatro y asume el rol de líder por su tranquilidad y madurez, representa la normalidad. Kyle es judío y altamente creativo con relación a los demás; Cartman es el niño egoísta, gordo, antisemita y xenófobo, y Kenny procede de la pobreza y se encuentra mucho tiempo silencio, no se en-

\section{Conclusiones}

Realizado este breve inventario de las series de dibujos animados emitidas en las últimas cuatro generaciones por la televisión colombiana, es posible determinar el siguiente marco axiológico, desde los referentes de la teratología, la adalidología, la entropía y los fractales, que se encuentra en los imaginarios éticos y estéticos que han formado los ciudadanos actuales.

La teratología (estudio de los Monstruos) ha mutado de década en década; los monstruos de la década de los setenta eran hombres personificados en demonios, satanes o malandrines; en los ochenta se presentaron con un sincretismo quimérico entre hombres, animales y cosas; para los noventa cuentan con corazas, armaduras y aparatos mecánicos y tecnológicos.

A principios de este milenio el monstruo se transformó significativamente, ya no se presenta mediante personas, centauros o máquinas; sino en el absurdo, los sinsentidos, las utopías sociales que se presentan de forma cruda e irreverente. Lo monstruoso dentro de la arista estética se ha transformado, desde una belleza apolínea a una sincretista, pasando por una tecnológica, para terminar en la belleza utópica. Así, los actuales ciudadanos buscan una belleza sinsentido, absurda e inexistente, que se caracteriza por no estar en el tiempo ni en el espacio, configurando un ciu- tiende lo que dice. Su caso es particular porque en las primeras temporadas era asesinado al inicio o al final de cada capítulo. No obstante, nunca moría por completo, reaparecía en los capítulos siguientes; a pesar de su perfil oculto, en las últimas temporadas se entiende lo que dice Kenny, y no lo han vuelto a matar.

El discurso de esta serie apunta a la contralógica ciudadana de integrar en los proyectos existenciales el más acá antes que el más allá. Estas ciudadanías se encuentran modeladas por procesos formativos higienizadores, profilácticos y de seguridad VIP, generando simultáneamente tendencias ultraliberales que buscan modelar un ciudadano hedonista pero, al mismo tiempo, comprometido con lo social. En esta misma perspectiva, se diseñan tendencias ciudadanas ultraconservadoras, que apuntan a ciudadanos competitivos y profesionales, pero ciudadanos narcisos y angustiados. Comparten sus características, series como los Simpson (2012, Cap. 1); Padre de familia (2013, Cap. 1); Popetown (La Villa del Papa, 2013, Cap. 1) o los Padrinos Mágicos (Magic Parents, 2011, Cap. 1). dadano cuyo influjo estético proviene de su estado de ánimo y de su razón de ser y de existir.

La adalidología (estudio de los héroes) ha corrido la misma suerte. Los superhéroes se han transformado con el paso del tiempo; los héroes mesiánicos de los setenta y parte de los ochenta fueron mutando hacia superhéroes y superheroinas caracterizados por su voluptuosidad y libidinosa belleza. Este modelo de superhéroe se erosionó hacia un héroe más sofisticado, más veloz, más tecnológico y por lo tanto más omnipresente; sin importar el tiempo y el espacio, este héroe se presenta en el momento que se le necesita, es el superhéroe de la ubicuidad.

En la primera década del primer milenio el héroe con el estereotipo de la belleza, la fortaleza y la omnipresencia es cambiado bruscamente por el héroe débil, exiguo y de bajo perfil, uno que sigue el patrón de Forrest Gump, con bajo perfil pero que logra el éxito por producto del azar. El mismo modelo de Bart Simpson, los niños de South Park, el protagonista de Padre de familia, entre otros. El superhéroe se encuentra dentro de una arista ética cuyas actuaciones morales no dependen de si están dentro de la bondad o la maldad. Las actuaciones giran en un estilo de vida que está pendiente del azar, de la ambivalencia y la ambigüedad. 


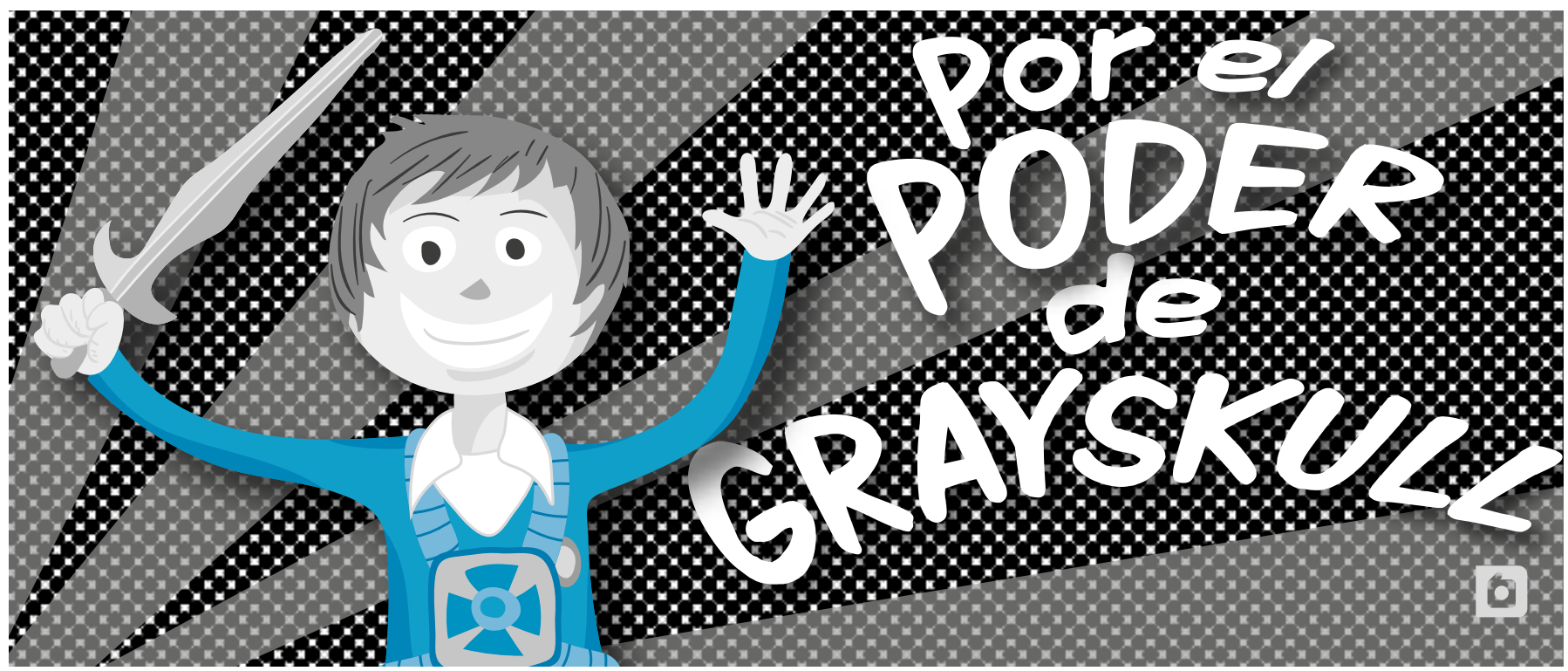

Este tipo de ciudadanía se enmarca dentro de lo que es conocido como los ciudadanos pusilánimes.

Los fractales (estudio de las regularidades e irregularidades) han tenido modificaciones sustanciales en materia axiológica, en cuanto a las relaciones entre ética y estética. Las asociaciones premodernas regulares, en alas que la bondad se relaciona con la belleza y la maldad con la fealdad, tal como se ven en las series de los setenta, tienen una primera distorsión en los ochenta, en los que la bondad se asocia con la fealdad y la maldad con la belleza; esta irregularidad proviene de la modernidad.

Sin embargo, las reales irregularidades se presentan durante los noventa y el nuevo milenio, con las asociaciones postmodernas donde los malos son buenos, los bellos son feos y viceversa. El mito perverso de los supercampeones... En la actualidad se encuentra en debate si fue o no fue así el final; profundizando el enigma de esta leyenda.

El mismo caso del fractal de los Caballeros del Zodiaco cuyo hilo conductor se desarrolla a partir de una lucha en un coliseo en donde se entretejen toda suerte de historias, culturas, creencias religiosas y dinamismos personales, así como avaricias, envidias e intereses particulares para obtener las respectivas armaduras. Las actuales ciudadanías son verdaderos fractales, el ciudadano es una cosa en la mañana, otra en la tarde y algo muy diferente en la noche. Este mismo ciudadano tiene dos o tres vidas que enmascara y desenmascara de acuerdo a sus necesidades vitales y existenciales. Así mismo, su lógica coherente es la incoherencia: porque lo que piensa no lo dice, si lo dice no se compromete y si se compromete no lo cumple.

En relación con las entropías (estudio de los órdenes y desordenes), se identifican discursos en las series que entrecruzan los órdenes con respecto a los desórdenes axiológicos. En estos programas, independientemente de la década y de la generación, se realizan apologías a las ciudadanías xenófobas, racistas y discriminatorias, modelando un ciudadano anfibológico o contradictorio.

Otro tipo de ciudadanía subterránea que emerge producto de estas influencias, se encuentra en la defensa del ciudadano neo-nacista, angelical y moralizante. El ciudadano Gran Hermano que regula y legisla la ética, la estética y la política de los demás. Finalmente, emergen ciudadanías cuyos componentes principales son individuos sin ninguna crítica. El ciudadano de la imagen, de la apariencia, de la efigie y la fachada, producto de una sociedad de consumo que desborda la libertad individual y colectiva, la misma que le jalona a consumir lo que no necesita pero que le hacer sentir bien. En estos escenarios emergen los ciudadanos ultraconservadores, que cuentan con un puritanismo que no permite la reflexión serena de los dinamismos éticos y estéticos que surgen cotidianamente. Igualmente, se desarrollan ciudadanías ultraliberales en las que no existen los límites, sino el todo vale, irrumpiendo o violentando no sólo las dinámicas colectivas de la sociedad, sino las internas de las personas. 


\section{Referencias}

Anderson, B.C. (2005). South Park Conservatives. The revolt against liberal media bias. U. S. A.: Regnery Publishing.

Calabrese, O. (1999). La Era Neobarroca. Madrid: Ediciones Cátedra.

Candy. (2012). Las Travesuras de Candy-Candy. Obtenido desde http:// www.youtube.com/watch?v=OBh_FgaALu4

Centella. (2011). Canción Letra en Español. Obtenido desde http:// dizponible.blogspot.com/2010/11/capitan-centella-gekko-kamen. html

Centella. (2005). Primer Capítulo de Centella. Obtenido desde http:// www.youtube.com/watch?v=91X0HwulzPM

Centuriones. (2010). Primer Capítulo de los Centuriones: Un nuevo Enemigo. Obtenido desde http://www.youtube.com/watch?v=g61deg8o-q0

Cogan, B. (2012). "Deconstructing South Park. Critical Examinations of Animated Transgretion". United State of America: Lexington Books.

Dragon Bal Z. (2013). Primer Capítulo de Dragón Ball Z: En Busca de las Siete Esferas del Dragón. Obtenido desde http://www.youtube. $\mathrm{com} /$ watch?v $=$ C_seLqTiSJ0
Digimon. (2012). Primer Capítulo de Digimon: La Aventura de Digimon. Obtenido desde http://www.youtube.com/watch?v=Ff3rg5I$\mathrm{cxWw}_{\mathrm{w}}$

Hanley, R. (2007). South Park and Philosophy. Bigger, Longer and Penetrating. U. S.A.: Popular, Culture and Philosophy.

Halcones Galácticos. (2012). Primer Capítulo de los SilverHawk. Obtenido desde http://www.youtube.com/watch?v=0LyzIEmLpnw

Heidi. (2012). Primer Capítulo de Heidi. Obtenido desde http://www. youtube.com $/$ watch?v $=\mathrm{Hb} 6 \mathrm{OK} 2 \mathrm{ZdKj} 8$

He-Man. (2012). Segundo Capítulo de He-Man. Obtenido desde http:// www.youtube.com $/$ watch? $\mathrm{v}=\mathrm{QfcSqMr} 4 \mathrm{ymk}$

Mazinger Z. (2011). Primer Capítulo de Mazinger Z: El Nacimiento de un Robot Milagroso. Obtenido desde http://www.youtube.com/ watch? ${ }_{\mathrm{v}}=\mathrm{REbcK} 9 \mathrm{D} 78 \mathrm{Ns}$

Meteoro. (2012). Primer Capítulo de Meteoro. Obtenido desde http:// www.youtube.com $/$ watch?v $=$ G57ZUrjIOKk

Padre de Familia. (2013). Primer Capítulo de Padre de Familia: Me Suena a Griego. Obtenido desde http://www.youtube.com/watch?v=yB6Cwmt_41U 
Padrinos Mágicos. (2011). "Primer Capítulo de los Padrinos Mágicos: El Gran Problema”. Obtenido desde http://www.youtube.com/watch?$\mathrm{v}=\mathrm{FQXrlYGo0Nc}$

Pitufos. (2013). Primer Capítulo de los Pitufos. Disponible en: http:// www.youtube.com $/$ watch? $\mathrm{v}=$ WS2bDzU5PIs

Pokemon. (2012). Primer Capítulo de Pokemon: Ash y sus Evoluciones. Obtenido desde http://www.youtube.com/watch?v=JoiO6UVp4R4

Popetown. (2013). Primer Capítulo de la Villa del Papa: El Doble. Obtenido desde http://www.youtube.com/watch?v=hlIntry7tYM

Robotech. (2013). Primer Capítulo de Robotech: El Señuelo. Obtenido desde http://www.youtube.com/watch? $\mathrm{v}=\mathrm{nF} 6 \mathrm{RIV} 2 \mathrm{Ycw} \mathrm{Y}$

Simpson. (2012). Primer Capítulo de los Simpson: El Coco. Obtenido desde http://www.youtube.com/watch?v=Twd7DxoHuk8

Sailor Moon. (2013). Primer Capítulo de Sailor Moon: La Niña Miedosa que se convierte en Sailor Moon. Obtenido desde http://www.youtube.com $/$ watch? $\mathrm{v}=\mathrm{vHNoD}-4 \mathrm{CPfk}$.
Stratyner, L., y Keller, J. R. (2009). "The deep end of South Park.Critical Essays on Tv's Shocking Cartoon Series”. U. S. A.: McFarland \& Company Publishers.

Superamigos. (2012). Primer Capítulo de los Superamigos: ¿Qué pasó con el Clima?. Obtenido desde http://www.youtube.com/watch?v=JZxldrIOwOI

Supercampeones. (2012). Primer Capítulo de los Supercampeones: El Desafío. Obtenido desde http://www.youtube.com/watch?v=dc0V8NKvbAM

Thundercats. (2011). Primer Capítulo de los Thundercats. Obtenido desde http://www.youtube.com/watch?v=nrdC5YccxwE

Transformers. (2008). Primer Capítulo de Transformers: El nombre es más de lo que ven los ojos. Obtenido desde http://www.youtube. $\mathrm{com} /$ watch?v=_3Rmsg6SSwQ

Weinstock, J. A. (2008). "Taking South Park Seriously”. U. S. A.: State University of New York Press Albany. 


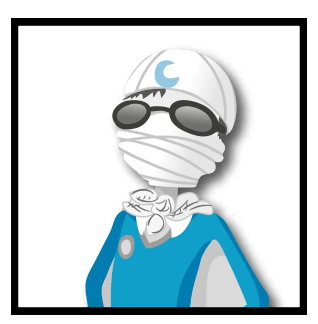

